\title{
Incorporating Inquiry Investigation into Language Arts Curriculum
}

\author{
Irina Lazareva* \\ Far Eastern Federal University, Department of Regional and International Studies, Russia \\ *Corresponding author: lazar_irina@mail.ru
}

Received September 29, 2014; Revised October 28, 2014; Accepted December 14, 2014

\begin{abstract}
The article includes methodological and practical applications for improving Foreign Language students' performance through incorporating inquiry investigation. The key to high-quality performance is found in systematicity and systematization of interrogative practice included in the mini-course on elementary research skills building. Question-and-answer method is presented from the vantage point of learner-centered approach promoting assistance in moving through the stages of disciplined inquiry, nurturing research competence and the culture of learning the World.
\end{abstract}

Keywords: disciplined inquiry, research competence, high-grade questions, Content-based guided inquiry learning

Cite This Article: Irina Lazareva, "Incorporating Inquiry Investigation into Language Arts Curriculum." American Journal of Educational Research, vol. 2, no. 12B (2014): 78-82. doi: 10.12691/education-2-12B-14.

\section{Introduction}

In the global age when having information is much less valuable than knowing how to think with information in novel situations, inquiry is a helpful method to scientifically address matters encountered in professional, social and personal life.

Doing research is intrinsic to going into higher education. In this nature of things, fostering research skills must be a corporate part of any program that guarantees high-grade academic training.

However, this is actually a complicated problem as research papers fall into category of complex human performances; involving so many skills that few students are able to do well on them without extensive instruction and practice (Van Gelder, 2005: 42). This paper conceptualizes a teaching experience of giving Foreign Language (FL) students (Far Eastern Federal University, Russia) grounding for research competence building.

\subsection{Theoretical Framework for Incorporating Methodology of Inquiry in Language Arts CLASSROOM}

Since the learner is the active agent in constructing meaning, knowledge and worldview, his mind must be "instrumental and essential in interpreting events, objects and perspectives on the real world" (Jonassen, 1991: 29). This circumstance determines the concern with teaching the methods of thinking for making careful observations, discovering relevant data and ideas, generalizing from data, analyzing, hypothesizing, making inferences, interpreting, posing problems, anticipating consequences, learning autonomously with a thirst for knowledge, to name a few.

The fundamental rationale of the paper has been John Dewey's philosophical propositions for the importance of inquiry-based teaching as a way of nurturing essential skills of lifelong learning for coping with the complexities of modern life and preserving values of the world (Dewey, 1938: 111).

Another foundational idea underlying innovative format of FL classroom is appraising the potentiality of studentgenerated questions (Marzano, 2014; Rosenshine, Meister, and Chapman, 1996; Tishman, Perkins, Jay, 1995) as a "high-yield strategy" (Marzano, 2009: 30) - classroom techniques that have research supporting their utility at enhancing student achievement".

\subsection{Rationale}

The new Competency-Based Education university curriculum is aimed at developing research competence recognized as a generic capacity applicable in every learning and professional area and viewed as a subset of higher order thinking skills and dispositions which students need to function productively in today's global society.

On the panel of proposed improvements high priority is being given today to developmental approach that sees thinking and learning as merging in instructional theory (Resnick \& Klopfer, 1989). Hence, teaching methods of thinking ought to be inclusive, i.e. infused into content learning.

There are a lot of inquiry programs designed to help students find out about science phenomena (Burgh \& Nichols, 2012) while in FL education new conceptualizations based on cognitive theory often pose a 
challenge (Wingate \& Tribble, 2012). Though teaching for research competence is asserted a part of a FL curriculum, very little actual time is spent by FL students doing inquiry activities. Teachers do extensive efforts to train students in FL functional literacy skills but miss the actual educational task to cultivate in students the skills of disciplined inquiry. As many graduate students lack skills of intelligent inquiry, the content of their research papers keeps below level - they can exercise at most superficial understanding of the subject matter and specious reasoning. Moreover, some of them do not have confidence or general knowledge of how to start exploration.

These problems are widespread and stem from the fact that up to the present day many instructional faculties choose to focus on teaching content and shy away from teaching generic skills. Foreign language instruction implements mostly the model of specific language skills training that serves to display patterns of weak thinking and low-order questions. When focusing on the lowest rung of the Bloom's taxonomy pyramid - memorizing, recalling, describing - engaged in are two-dimensional and casual classroom activities not associated with guiding exploration. Thus, students are unprepared for research writing because they are not taught methodology of thinking.

The traditional forms of FL practices or ventures to bring students into inquiry-based tasks without explicit teaching core skills fall short of a goal to nurture the disciplined mind. Also, teaching research competence intermittently comes to no good. On the other hand, teachers need and deserve a great deal of assistance in putting inquiry teaching into practice (Anderson, 1998).

So, recognizing the need for higher levels of skills, another course of action was adopted which resulted in raising the stakes and experimenting with an alternative format of FL classroom called Content-Based Guided Inquiry Learning (CBGIL).

\section{Inquiry Driven Classroom}

Embedded into the FL curriculum the micro-course is supported by topical readings with real-life problematics. But even though carefully selected, this may be ineffective without facilitating reflection on underlying meanings and interpretations. So, in addition to the development of the four basic language skills, the mini-course cultivates the culture of disciplined inquiry supposed to get students to think more carefully about what they are reading, writing or talking about. In point of fact, CBGIL is a course in which research is not viewed as a complex form to be mastered but as a means of deepening intellectual and emotional involvement with a subject. My specific concern was to provide an elementary basis to help students cope with future research paper they will have to write in their formal university classes, while at the same time master useful life skills of investigating the world. The course blends two kinds of courses normally separated in the FL curriculum: the content-based course in which language is taught indirectly through the medium of a specific subject matter (Brinton, Snow, \& Wesche, 1989) and a thinking-based class (Beyer,1983; Costa, 2008; Perkins, 1995). Such an approach combines the strengths of both kinds of courses: language, content, and thought-centered methodology.

\subsection{Content-based Guided Inquiry Learning: Components}

The basic essentials of the mini-course on guided disciplined inquiry (Table 1) include: specific topical content, integrating macro-skills, expository instruction, team work, guided-inquiry activities, modeling questions, student-initiated questions to promote investigation inquiry, metacognitive awareness, reporting, individual responsibility. These components may be esteemed as tools to develop research skills and specific topical content.

Table 1. Critical components of the Content-based guided inquiry learning

\begin{tabular}{|c|c|c|}
\hline Team work & Individual responsibility & $\begin{array}{c}\text { Specific topical } \\
\text { content }\end{array}$ \\
\hline $\begin{array}{c}\text { Modeling } \\
\text { activity }\end{array}$ & $\begin{array}{c}\text { Questions to promote inquiry } \\
\text { investigation }\end{array}$ & Reporting \\
\hline $\begin{array}{c}\text { Integrating } \\
\text { skills }\end{array}$ & Guided-inquiry activities & $\begin{array}{c}\text { Metacognitive } \\
\text { awareness }\end{array}$ \\
\hline
\end{tabular}

Integrating skills. The course leads to specific outcomes pertaining the development of language skills (listening, speaking, reading, and writing) and process skills (scientific methods of information processing and complex reasoning, metacognitive knowledge, habits of mind, as well as social skills of effective communication and collaboration) within content- and task-based activities. Linguistic forms and functions are considered as partial aspects of what is to be learnt, and language is organized around experiences that are immediate to students. In turn, cognitive operations of organizing, developing and expressing, creating and exchanging ideas, lead students to gain better linguistic competence. Such an approach where language acts as a medium of fostering intellectual thinking requires taking an extra step towards the formation and development of reading, writing and speaking skills of a very high order.

Specific topical content. In the content-based research approaches form is always practiced within a specific content. This helps students see the relevance of an inquiry skill (e.g. analysis) that will soon be extended to their research papers. The course promotes active learning through exploiting intellectually-challenging texts that engage students in doing mini-research. The teacher provides the specific texts as cases, situations or examples that students will investigate as they are guided to make conceptual discoveries. Investigation into an issue acts as not only a byproduct of the course but an integral concern of learners as well.

Modeling activity. Basic thinking abilities must be taught directly and explicitly (Chaffee, 1992; Perkins \& Salomon, 1988). Hence, expository teaching is an effective way of organizing methodology of inquiry learning. The utilization of abstract structures for thinking is preceded by the modeling procedure. The teacher presents a new speculative instrument in an organized fashion checking to make sure the student is subsuming the new information. The research evidence suggests that most students will not learn thinking skills without explicit attention to helping them do so.

Group work. Cooperative methods are rooted in Piagetian and Vygotskian traditions that emphasize the value of social interactions for promoting cognitive 
development. The central task of research - thinking critically about the text - is enacted in the helpful and stimulating environment of a classroom where they build a base of common experience which assists them in the process of sharing and communicating. If students are encouraged to work in teams, they are not left on their own as they are trying to understand and think beneath the surface. Instead, articulating their observations, ideas and questions they have the chance to elicit background knowledge, see other points of view, refine their ideas in discussions, support each other's understanding.

Reporting. A written report is submitted by each team at the end of the inquiry session. They may contain the team answers to the questions they were addressed during the session, a summary of the important concepts, statements, reasoning that they developed from the activity. The report gives students the opportunity to assess their performance and reflect what they have learned.

Individual responsibility. Students need to work to develop their own inquiry skills. For this reason it is essential that they be held individually responsible for their learning. To assure individual responsibility the instructor provides evaluation both of individuals and of the team. It encourages all students in a team to participate since the instructor's points may differ for different team members.

Metacognition, the process of planning, assessing, and monitoring one's own thinking in order to develop understanding. Actually, if the students do the steps but do not understand why they did them hands-on activities are just like rote learning. It must be kept in mind that the final outcome of thought-focused instruction is development of students' self-awareness of their own thinking, which means enabling them to monitor their act of learning, and thinking and involving them in a conscious development of skillful thinking (Niedringhaus, 2010).

Guided-inquiry activities are designed to improve performance in higher order thinking skills. They may take several forms, including analysis, problem solving, discovery and creative activities, both in the classroom and the community. The main point is to provide structured opportunities which stimulate and guide students to actively think for themselves reflecting on author's purpose, representing the point of view, role playing, discussing ideas, deconstructing textual information, drawing logical conclusions based on interpretation, developing principles, understanding performances, etc. Upon that the situation is structured into linking subtasks to ensure that the learners can cope with it with their existing resources.

To make skilful thinking a classroom reality we need a clear vision of investigation activity.

The scheme of inquiry cycle derived from a synthesis of research (Collins \& Stevens, 1983; Gunawardena et al., 2006; Pascarella \& Terenzini, 1991) has been applied in the course to assign the structure. Summarized, the phases are as follows.

1. Observation / Identification of a problem. Students are challenged to become mentally engaged in the concept to be learned.

2. Exploration of ideas, concepts, statements, problems. Students are led to think beneath the surface, at a higher end of cognitive taxonomy to determine what the sender of the text message means. Operations that may occur in this phase might include identification of differences in understanding of terms, concepts, schemas and questions to clarify the extent of disagreement.

3. Generating deep understanding. Negotiation of meaning and/or co-construction of knowledge under the lens of critical examination. The construction of new knowledge process as students share and compare their observations and understandings with others.

4. Meaning construction. Modification of proposed synthesis or co-construction and phrasing of agreement, statement(s), and application of the newly constructed meaning. This phase encompasses summarizing agreement(s) and metacognitive statements that illustrate new knowledge construction and application.

5. Evaluation determines if the learner has attained understanding of concepts. At this stage the learner decides how he/she feels about the message, its personal significance or meaning.

6. Raising a new issue. This stage is based on the concepts students have learned, and connections to other related concepts that often lead to further inquiry and new understandings.

Though this sequence oversimplifies the process of doing inquiry which in any discipline is not strictly linear but messy, and at times idiosyncratic, it allows students to see inquiry investigation in a very basic and fundamental way. The logic of the scientific method is present in a structured fashion of CBGIL activities that model the stages of research process.

Inquiry-based learning is an approach to learning that involves a process of exploring the natural, empirical, and material world, which leads to asking many questions, making discoveries, and rigorously testing them in the search for new understanding (Foundations, 2001). It is high-quality research questions that guide inquiry and help to construct meaning in the light of the text deep understanding.

\subsection{Higher-Order Questioning as a Basic Inquiry Technique}

The major portion of the inquiry session is devoted to the students' asking questions. In the suggested minicourse higher-level questioning is positioned as the core component of inquiry process facilitating the search for authentic meaning throughout the whole process. The CBGIL esteems the ability to ask higher-level questions as a necessary instrumentality for students to increase inquiry competence; reading passages containing problems real and relevant to students, as a stimulus for jumpstarting student-generated questions. The course is designed to gradually introduce sequencing questions operating as a wellspring of inquiry, tools guiding inquiry, and in sequence, a technique crowning the investigation by creating a new issue.

To monitor wording of questions; the typology of question stems as a training instrument to improve students' questions may be suggested at the initial stage. In the instant case the students were invited to create a 
toolkit of high-grade questions through their individual effort resorting to the practice of identification and matching questions and answers within investigating a specific concept. The students were given the opportunity to reflect what counts as friendship to themselves and others. As concepts cannot be established like facts learners had to consider a range of possible meanings that prompt deep questions leading to contestable answer. Doing this, they are involved in active learning of cognitively complex language units and the language of reasoning (Table 2).

Table 2. Operation-centered activity: Identifying attributes of high-grade questions

\begin{tabular}{|c|c|c|c|c|c|}
\hline \multicolumn{6}{|c|}{$\begin{array}{r}\text { Task: Study the message and high-grade questions that lead to contestable } \\
\text { these questions. Then organize }\end{array}$} \\
\hline \multicolumn{3}{|c|}{ What is the key point made by the author? } & \multicolumn{3}{|c|}{ Books and friends should be few but good } \\
\hline \multicolumn{3}{|c|}{ What notion helps organize this representation? } & \multicolumn{3}{|c|}{$\begin{array}{c}\text { Friendship isn't about whom you have known the longest... It's about } \\
\text { who came, and never left your side... }\end{array}$} \\
\hline \multicolumn{3}{|c|}{ Can you provide a definition for the notion presented? } & \multicolumn{3}{|c|}{ Many people value friendship for what can be gotten out of it. } \\
\hline \multicolumn{3}{|c|}{ Can you make a distinction between friendship and good fellowship? } & \multicolumn{3}{|c|}{ Hold a best friend with both your hands. } \\
\hline \multicolumn{3}{|c|}{ What would you compare it to? } & \multicolumn{3}{|c|}{$\begin{array}{c}\text { There comes a point in your life when you realize who really matters, } \\
\text { who never did, and who always will. }\end{array}$} \\
\hline \multicolumn{3}{|c|}{ What details can you add to make this idea feel more complete? } & \multicolumn{3}{|c|}{ A good friend } \\
\hline \multicolumn{3}{|c|}{ Can you propose an alternative? } & \multicolumn{3}{|c|}{ Someone who helps you when you are in trouble is a real friend. } \\
\hline \multicolumn{3}{|c|}{ What conclusion can you draw? } & \multicolumn{3}{|c|}{ A friend is the one who comes in when the whole world has gone out. } \\
\hline \multicolumn{3}{|c|}{ How would you justify the trend to weakening of solid friendly ties? } & \multicolumn{3}{|c|}{$\begin{array}{l}\text { If all my friends were to jump off a bridge, I wouldn't jump with them, } \\
\text { I would be at the bottom to catch them. }\end{array}$} \\
\hline \multicolumn{3}{|c|}{ How would you assess the value of friendship? } & \multicolumn{3}{|c|}{$\begin{array}{l}\text { Best friends are like diamonds, precious and rare. False friends are like } \\
\text { leaves, found everywhere }\end{array}$} \\
\hline \multicolumn{3}{|c|}{ What follows from the matter under discussion? } & \multicolumn{3}{|c|}{ Only your real friends will tell you when your face is dirty. } \\
\hline \multicolumn{3}{|c|}{ How and where can we use this knowledge? } & \multicolumn{3}{|c|}{$\begin{array}{c}\text { When you have a good friend on the uneven path of life, everything is } \\
\text { easier. }\end{array}$} \\
\hline \multicolumn{3}{|c|}{$\begin{array}{l}\text { Table } 2 \text { presents cognitive processes - analysis, } \\
\text { inference, evaluation, transfer - that help to organize } \\
\text { substantive questions into a toolkit of major types of } \\
\text { questions that drive inquiries in the search of new } \\
\text { understandings. } \\
\text { - Analysis questions investigate the nature of } \\
\text { something by eliciting its constituent elements. } \\
\text { - Inference questions require the student to recognize } \\
\text { implied meaning. }\end{array}$} & \multicolumn{3}{|c|}{$\begin{array}{l}\text { - Evaluation questions help you to place a value on } \\
\text { ideas and make judgments } \\
\text { - Transfer questions provoke a kind of breadth of } \\
\text { thinking, asking students to take their knowledge to } \\
\text { new places. } \\
\text { Students establish that all necessary attributes are } \\
\text { present to qualify a question for a category. } \\
\text { It is advisable that they gradually complete the matrix } \\
\text { in due course time. }\end{array}$} \\
\hline \multicolumn{6}{|c|}{ Table 3. Creating a toolkit for high-grade questions } \\
\hline $\begin{array}{l}\text { Analysis } \\
\text { questions }\end{array}$ & $\begin{array}{l}\text { What is the key } \\
\text { point..? }\end{array}$ & $\begin{array}{l}\text { What notion helps to } \\
\text { organize ..? }\end{array}$ & $\begin{array}{l}\text { Can you provide a } \\
\text { definition...? }\end{array}$ & $\begin{array}{l}\text { Can you make a } \\
\text { distinction..? }\end{array}$ & $\begin{array}{l}\text { What would you } \\
\text { compare it to? }\end{array}$ \\
\hline $\begin{array}{l}\text { Inference } \\
\text { questions }\end{array}$ & $\begin{array}{l}\text { What details can } \\
\text { you add..? }\end{array}$ & $\begin{array}{l}\text { Can you propose an } \\
\text { alternative? }\end{array}$ & $\begin{array}{l}\text { What conclusion can } \\
\text { you draw? }\end{array}$ & & \\
\hline $\begin{array}{l}\text { Evaluative } \\
\text { questions }\end{array}$ & $\begin{array}{l}\text { How would you } \\
\text { justify..? }\end{array}$ & $\begin{array}{l}\text { How would you assess the } \\
\text { value..? }\end{array}$ & & & \\
\hline $\begin{array}{l}\text { Transfer } \\
\text { questions }\end{array}$ & $\begin{array}{l}\text { What follows } \\
\text { from..? }\end{array}$ & $\begin{array}{l}\text { How and where can we use } \\
\text { this knowledge? }\end{array}$ & & & \\
\hline
\end{tabular}

On completing the task students obtain a bank of substantive questions organized into the user-friendly toolkit. As the procedure of inquiry is framed around questions students learn that in order to obtain information, understand the real problem, account for the focus event, they must ask thoughtful questions. Provided sufficient systematicity and systematization, higher order questioning may become the students' initial method of doing research.

Although some teachers might find such an intensive focusing on interrogative strategy restrictive, I find this way of teaching for research competence more effective than the traditional approach due to the following reasons:

- Student-sourced questions shift the burden of thinking onto the learners.

- With the use of substantive questions students examine the data closely and explore a phenomenon until it becomes less mysterious.

- High grade questions have a potential application in a number of academic and cross-cultural contexts.

\section{Conclusions}

Herein before the author provides a vision of how a course that is targeted at inquiry competence development might be organized in the Language Arts classroom.

In response to the requirements of transforming foreign language education programs from rote to meaningful learning, Content-Based Guided Inquiry Learning (CBGIL) course is trying out new, more effective mode in FL teaching that reinforces the perspective of upgrading quality standards from two-dimensional low-level learning (recalling, literal comprehension, application) to the development of students' complex thinking, power of interrogation, and investigative frame of mind.

In reliance on its developmental purposes the ContentBased Guided Inquiry Learning can be considered quite a promising innovation that encourages the perspective of helping students to use FL to acquire questioning methodology as the central core skill for doing research. Nine components as the tools for developing language, 
cultural and process skills are reflected (specific topical content, integrating skills, expository instruction, guidedinquiry activities, modeling questions, student-generated questions, meta-cognitive awareness, reporting, team work, individual responsibility). A structured approach organized around substantive student-sourced questions turns passive consumers of ready-to-use information into active investigators of existential problems. The experience of high intellectual quality enables FL students to move from fact and observation towards inference, interpretation and new meaning and message construction.

Exercising more frequent and effective use of higherlevel questions in FL classroom makes students better learners and better inquirers - which, after all, is the goal of the "Content-Based Guided Inquiry Learning" course.

Further research needs to be done on whether FL students use the technique of high-grade questioning at their own motion when climbing the tree of knowledge, and how effectively they would ask high-grade questions with no outside help.

\section{Acknowledgment}

I would like to thank all my colleagues at the Far Eastern Federal University who piloted earlier version of the Content-Based Guided Inquiry Learning course. Special thanks also to my students, the catalysts for all these ideas.

\section{References}

[1] Anderson, R.D. (1999). Inquiry in the everyday world of schools Focus: a magazine for classroom innovators (special issue), 6 (2).

[2] Beyer, B.K. Common sense about teaching thinking skills (1983) Educational Leadership. 41 (3). 44-49.

[3] Brinton, D.M., Snow, M.A. \& Wesche, M.B. (1989). Contentbased second language instruction. New York: Newbury House.

[4] Burgh, G., \& Nichols, K. (2012). The parallels between philosophical inquiry and scientific inquiry: Implications for science education. Educational Philosophy and Theory, 44(10), 1045-1059.

[5] Chaffee, J. (1992). Teaching critical thinking across the Curriculum. San Fransisco: Jossey- Bass.
[6] Perkins, D.H., \& Salomon, G. (1988). Teaching for Transfer. Educational Leadership, 46, 22-32.

[7] Collins, A., Stevens, A. (1983). A Cognitive Theory of Inquiry Teaching. In Reigeluth, C.M. (Ed.) Instructional Design Theories and Models: An Overview of Their Current Status Instructionaldesign theories: An overview of their current status. Hillsdale, NJ: Lawrence Erlbaum Associates Publishing. pp. 247-278.

[8] Costa, A.L. (2008). The thought-filled curriculum. Educational Leadership. 65 (5). 20-24.

[9] Dewey, J. (1938). Experience and Education. New York: Macmillan.

[10] Gunawardena, C. N., Ortegano-Layne, L., Carabajal, K., Frechette C., Lindemann, K. \& Jennings, B. (2006). New model, new strategies: Instructional design for building online wisdom communities. Distance Education, 27 (2), 217-232.

[11] Jonassen, D.H. (1991). Evaluating constructivist learning. Educational Technology, 28 (11), 13-16.

[12] Marzano, R. (2009) Setting the record straight on "high-yield" strategies. Phi Delta Kappan Journal of Reading, 91 (1), 30-37

[13] Marzano, R., Simms, J. (2014). Questioning sequences in the classroom. Marzano Research Laboratory.

[14] National Research Council 2001, Foundations - Volume II: Inquiry; thoughts views, and strategies for the $K-5$ Classroom. NSF Division of elementary, secondary, and informational education. Retrieved May 26, 2014 from http://www.nsf.gov/pubs/2000/nsf99148/htmstart.htm

[15] Niedringhaus, K. L. (2010). Teaching better research skills by teaching metacognitive ability. Perspectives: Teaching Legal Research and Writing. 18 (2). 113-118.

[16] Pascarella, E.T., Terenzini, P.T. (1991). How college affects students: Findings and Insights from Twenty Years of Research. San Francisco, CA: Jossey-Bass, 219 p.

[17] Perkins, D.N. (1995). Outsmarting IQ: The emerging science of learnable intelligence. New York: Free Press

[18] Resnick, L.B. \& Klopfer, L.E. (1989). Toward the thinking curriculum: Current cognitive research. Alexandria, VA: Association for Supervision and Curriculum Development Yearbook.

[19] Rosenshine B., C. Meister, and S. Chapman (1996). Teaching Students to Generate Questions: A Review of the Intervention Studies. Review of Educational Research, 66 (2). 181-221.

[20] Tishman, S., D. N. Perkins, and E. Jay. 1995. The thinking classroom: Learning and teaching in a culture of thinking. Boston: Allyn and Bacon.

[21] Van Gelder, T. (2005). Teaching critical thinking: Some lessons from cognitive science. College Teaching. 53 (1). 41-46

[22] Wingate, U. \& Tribble, C. (2012). The best of worlds? Towards an English for Academic Purpuses. Studies in Higher Education, 37 (4), 481-495. 